\title{
Adapting the WEPP hillslope model to predict unpaved road soil erosion in southern China
}

\author{
Longxi Cao ${ }^{1}$, Ting Zhang ${ }^{1}$, and Yi Wang ${ }^{2}$ \\ ${ }^{1}$ Chengdu University of Technology \\ ${ }^{2}$ Sichuan Normal University
}

August 4, 2021

\begin{abstract}
Process-based erosion models are efficient tools that can be used to predict where and when erosion occurs. On unpaved roads that have been recognized as important sediment sources, soil loss along road segments should be precisely predicted. This study was performed using the hillslope version of the Water Erosion Prediction Project (WEPP) to estimate soil loss from 20 typical road segments in the red soil region of South China. Terrestrial laser scanning (TLS)-measured soil losses were used to validate the model simulations. The results showed that the WEPP model could reasonably predict the total soil loss in relatively short (less than $100 \mathrm{~m}$ ) and gentle (slope gradient lower than 10\%) road segments. In contrast, the WEPP-simulated soil loss was underestimated for long or steep road segments. Detailed outputs along roads revealed that most of the peak soil loss rates could not be adequately calculated. The linear critical shear stress and the sediment equilibrium theory in the WEPP model for soil detachment simulation might be responsible for the underestimation. Additionally, the lack of upslope flow and the curved road tortuosity were found to be connected to the relatively low efficiency of the model outputs. Nevertheless, the WEPP simulation could accurately fit the trend of soil loss variation along road segments despite underestimation. Furthermore, the simulated results could provide a reliable prediction of the maximum soil loss positions. Therefore, the WEPP model could be adopted to evaluate the erosion risk of unpaved roads in the red soil region of South China.
\end{abstract}

\section{Adapting the WEPP Hillslope Model to Predict Unpaved Road Soil Erosion in Southern China} Longxi Cao ${ }^{1,2}$, Ting Zhang ${ }^{1}$, Yi Wang ${ }^{3 *}$

1. College of Ecology and Environment, Chengdu University of Technology, Chengdu, 610059, China

2. Institute of Soil Science, Chinese Academy of Sciences, Nanjing, 210008, China

3. Key Laboratory of Ministry of Education on Land Resources Evaluation and Monitoring in Southwest China, Sichuan Normal University, Chengdu, 610066, China

Corresponding Author: Yi Wang

No. 5 Jing'an Road, Chengdu, China

Postcode: 610066

E-mail: wang1984yi@126.com

Running Title: Adapting WEPP to predict road erosion

Abstract: Process-based erosion models are efficient tools that can be used to predict where and when erosion occurs. On unpaved roads that have been recognized as important sediment sources, soil loss along road segments should be precisely predicted. This study was performed using the hillslope version of the 
Water Erosion Prediction Project (WEPP) to estimate soil loss from 20 typical road segments in the red soil region of South China. Terrestrial laser scanning (TLS)-measured soil losses were used to validate the model simulations. The results showed that the WEPP model could reasonably predict the total soil loss in relatively short (less than $100 \mathrm{~m}$ ) and gentle (slope gradient lower than 10\%) road segments. In contrast, the WEPP-simulated soil loss was underestimated for long or steep road segments. Detailed outputs along roads revealed that most of the peak soil loss rates could not be adequately calculated. The linear critical shear stress and the sediment equilibrium theory in the WEPP model for soil detachment simulation might be responsible for the underestimation. Additionally, the lack of upslope flow and the curved road tortuosity were found to be connected to the relatively low efficiency of the model outputs. Nevertheless, the WEPP simulation could accurately fit the trend of soil loss variation along road segments despite underestimation. Furthermore, the simulated results could provide a reliable prediction of the maximum soil loss positions. Therefore, the WEPP model could be adopted to evaluate the erosion risk of unpaved roads in the red soil region of South China.

\section{Key words: road erosion; erosion modelling; WEPP; terrestrial laser scanning; South China}

\section{INTRODUCTION}

Unpaved roads are common man-made geographical features that are distributed in agricultural or forested watersheds (Tarolli, 2016). Road construction will change the underlying topography and alter the surface hydrology (Wemple et al., 2017). In turn, runoff generation is enhanced and results in a higher soil loss risk than that in other land-use types, such as farmland (Ziegler and Giambelluca, 1997; Cao et al., 2021). Furthermore, roads may accumulate, deliver, or increase sediment in runoff (Gucinski et al., 2001; Ramosscharrón, 2021). Therefore, unpaved roads have been reported to contribute a large proportion of sediment yield in a watershed, although they generally occupy a small fraction of the area (Ziegler and Giambelluca, 1997; Motha et al., 2004; Dangle et al., 2019; Ramos Scharrón, 2021; Yang et al., 2021). Road-related sediment that is routed to water bodies such as lakes and rivers can cause serious damage to the aquatic environment and impair the beneficial uses of surface water resources (Cole et al., 2020). Thus, road erosion should be considered one of the main sediment sources and should be properly evaluated (Cao et al., 2015; Zhao et al., 2021; Benda et al., 2019; Guo et al., 2021).

Soil erosion models are effective tools for road erosion evaluation (Elliot, 2009). During the last 20 years, different models have been applied and developed in road-related soil loss prediction. For example, the USLE (Universal Soil Loss Equation, Wischmeier and Smith, 1965) and its modifications have been used to estimate sediment production from forest roads (Sheridan et al., 2006). Scientists in North America have developed several empirical models to predict annual road sediment; examples include the SEDMODL (Boise Cascade Corporation, 2003), WARSEM (Dubé et al., 2004), ROADMOD (Anderson and Macdonald, 1998) and READI (Benda et al., 2019) models. Some of these models have also been applied in other regions, such as Australia (Fu et al. 2008), China (Cao et al., 2011a), Iran (Parsakhoo et al. 2014) and Turkey (Akay et al. 2008). However, as empirical road erosion models are mainly based on research in local regions, they are difficult to apply to areas with different environmental characteristics. Furthermore, most of the abovementioned empirical models can evaluate only the total annual road soil loss.

Process erosion models are widely used due to their inherent physically based capabilities for estimating the spatial and temporal distributions of soil losses (Zhang, 2017). The Water Erosion Prediction Project (WEPP) is a physically based, distributed model that simulates the detachment, transport and deposition of sediment by surface runoff (Nearing et al., 1989). It is one of the most popular process-based models that has been adopted around the world (Dun et al., 2009; Zhang 2017; Kinnell et al., 2018; Fernández and Vega, 2018; Zheng et al., 2020; Revuelta-Acosta et al., 2021). Elliot et al. (1995) proved that the WEPP hillslope version could be an efficient tool for estimating soil loss from unpaved forest roads. Based on a database of road-related soil and terrain files, the US Forest Service has developed a specific interface named WEPP: Road for forest road erosion estimation (Elliot, 2013). With the help of GPS and GIS technologies, the WEPP: Road could be adopted to predict soil loss from road networks at the watershed scale (Brooks et al., 2006). The hillslope version of the WEPP has also been used to predict sediment yield from road 
segments. For example, Brown et al. (2013) simulated soil loss from forest roads with the WEPP model and evaluated the effect of management practices in reducing sediment delivery to streams. Guerra and Silva (2011) adopted the WEPP model to predict sediment generation from 4 road segments. In most of the above studies, the WEPP model was used to evaluate the total soil loss from road segments and then validated with field sediment yield data from sediment traps. It should be noted that the WEPP is a process-based model and can simulate the detailed soil loss spatially, specifically along a hillslope. This information is of vital importance for road erosion risk evaluation and precise conservation. However, it is difficult to validate the detailed model results along a road segment using only the total soil loss information (Zhang, 2017).

Terrestrial laser scanning (TLS) technology can generate high-resolution micro-terrain data based on a 3D point cloud. With the help of TLS technology, scientists can precisely measure the detailed erosion volume and morphology information along eroded rills (Vinci et al., 2016; Renschler and Zhang, 2020). Cao et al. (2021) quantified rill erosion with high precision along road segments and explored the influential factor with TLS technology. The results verified the reliability of adopting TLS technology for erosion measurement on smooth road surfaces. Therefore, the measured erosion information should be helpful in validating the WEPP-simulated soil loss along road segments. This study was conducted based on our previous TLS-aided road erosion measurements. Soil losses from road segments were simulated by the WEPP hillslope version. The objectives of this study were to (1) validate the precision of the WEPP model in predicting soil loss along road segments of different lengths and slope gradients, and (2) explore the unique factors that determine the model efficiency in unpaved road conditions. The results are beneficial for enlarging the scope of application for the WEPP model, and they are also helpful for road erosion risk evaluation and conservation.

\section{MATERIALS AND METHODS}

\subsection{The Study Site}

The Zhuba watershed in Fujian Province of Southeast China (116 00'45" 116deg39'20"E, $25 \operatorname{deg} 18^{\prime} 40 " \sim 26 \operatorname{deg} 02^{\prime} 05 " N$ ) was chosen as the study site. It is a typical hilly small watershed with an area of $2.32 \mathrm{~km}^{2}$. The study site is dominated by a wet subtropical monsoon climate with an average annual precipitation of $1795 \mathrm{~mm}$, among which approximately $75.7 \%$ occurs in the wet season (from March to August). The elevation in the watershed ranges from $324 \mathrm{~m}$ to $646 \mathrm{~m}$ above sea level, and the average slope is 23 degrees. The local soil is derived from granitic weathered materials and is characterized by a coarse texture, low organic matter and high erodibility (Shi, 1985). The study site is a forested watershed, and approximately $50 \%$ has been opened for Camellia oleifera planting. An unpaved road network with a total length of $23.97 \mathrm{~km}$ was built in 2011. The road widths range from $3 \mathrm{~m}$ to $5 \mathrm{~m}$ to allow small vehicles to pass through for $C$. oleifera maintenance. Due to the low engineering standards, most of the roads were built by simply removing the topsoil downhill with a crawler tractor without erosion conservation measures. Serious rill erosion along roads and gullies can be found in some cases. To ensure that road surfaces are passable for vehicles, the road surface should be maintained, and rills should be filled or cleaned after the wet season. More details about the road network and soil loss can be found in Cao et al. (2021).

\subsection{TLS-aided Road Erosion Measurement}

Before the TLS erosion measurement, 20 road segments were chosen throughout the watershed by field survey in November 2018. These road segments were characterized by different slope gradients, lengths and surface erosion conditions and were therefore representative of the road network at the study site. Each road segment could be treated as a hillslope starting from the high point to the adjacent low ending point. One road segment is hydrologically independent from other road segments and therefore contains an entire process of erosion initiation, intensification and general deposition at the ending point (Cao et al., 2021). The TLS measurement was conducted with a FARO Focus S150 3D Laser Scanner. The scanning speed was 97,600 points per second with a point cloud density of $1.5 \mathrm{~mm}$ at a $10 \mathrm{~m}$ distance. In most cases, road surface rill micro-terrain was measured using a station scanning manner along roads with average intervals of approximately $10 \mathrm{~m}$. More than one scan would be performed at a site if the site had intensive rill erosion or complicated terrain conditions. With the help of CloudCompareV2.9.1, the original point cloud data could 
be registered and then converted to a $0.05 \mathrm{~m}$ resolution raster digital elevation model (DEM). According to the DEM data, road surface rills could be extracted, and erosion amounts could be calculated with the Spatial Analyst Tools in the ESRI ArcGIS 10.3 environment. Detailed information on the measured road segments and the process for road surface rill extraction has been demonstrated by Cao et al. (2021). Table 1 lists the TLS-measured road segment terrain factors and erosion rates.

[Insert Table 1]

\subsection{Road Erosion Modelling}

The WEPP hillslope version 2012.8 was used to predict soil loss from road segments in this study. The model simulates water and sediment detachment and transport through a series of overland flow elements (OFEs) (Brooks et al., 2006). According to the field survey, road surface rill erosion is the dominant erosion form throughout the road networks in the watershed. Therefore, the road surface was simulated as an OFE for each segment. There are four input files required to run the hillslope WEPP model: 1) the climate file describing the temporal variability of weather data; 2) the soil file containing the textural and hydraulic properties of the soils in each OFE; 3) the slope file including the steepness along the hillslope profile; and 4) the plant/management lists of the specific management scenarios and plant growth properties for each OFE.

\subsubsection{The Climate File}

The climate data used in this study were recorded by the Hetian Soil and Water Conservation Monitoring Station, which is approximately $5 \mathrm{~km}$ from the Zhuba watershed. Since the TLS measurement was conducted in late 2018 and the roads were maintained in last November, the weather data for both 2017 and 2018 were considered (Figure 1). The monthly averaged precipitation, wet days, maximum temperature, and minimum temperature for the two years were collected to create a custom PAR file with the Rocky Mountain Research Station Climate Generator (https://forest.moscowfsl.wsu.edu/cgi-bin/fswepp/wr/wepproad.pl). In turn, the PAR file was uploaded to CLIMGEN (Nicks et al., 1995) in WEPP Windows to create a 2-year daily average climate file.

\section{[Insert Figure 1]}

\subsubsection{The Soil File}

The local soils are derived from a layer of highly erodible sandy granite weathered material with a thickness of approximately $20 \mathrm{~m}$ (Shi, 1985). Due to road construction disturbance, the original topsoil layers were removed, and road surfaces were composed of coarse granite materials. Surface soil samples were taken from each road segment to determine property indexes. The soil texture in the study area is sandy loam with average contents of $65.24 \%$ sand, $19.02 \%$ silt and $15.74 \%$ clay. Soil organic matter was measured to range from 2.64 to $5.97 \mathrm{~g} / \mathrm{kg}$ with an average value of $4.33 \mathrm{~g} / \mathrm{kg}$. The averaged cation exchange capacity (CEC) was measured as $4.67 \mathrm{meq} / 100 \mathrm{~g}$.

The rill erodibility, critical shear stress, interrill erodibility and effective hydraulic conductivity are the most sensitive parameters for WEPP modelling. Elliot and Hall (2010) provided a parameter database according to soil texture, road design and road traffic level. We cited this database in the WEPP: Road interface by selecting road surface soil texture as sandy loam, road design as insloped bare ditch, road surface as native and traffic level as low. The soil parameters used for WEPP modelling in this study are listed in Table 2.

[Insert Table 2]

\subsubsection{The Terrain File}

The terrain files were created according to the detailed topography information measured by TLS technology. First, the elevation profile was extracted from the 0.05 m-resolution TLS DEM with the central line of each road segment. In turn, the road segment was divided into subsegments according to the elevation profile variation along the road. The subsegments were characterized as having a homogeneous slope gradient, and 
the length ranged from $10 \mathrm{~m}$ to $50 \mathrm{~m}$, which was determined by both the gradient variation and the total road length. After road segmentation, the slope gradient could be calculated for each subsegment by dividing the length by the elevation difference. Then, both the slope gradient and the length data of subsegments were inputted to the WEPP Slope Profile Editor, and finally, a terrain file was created for a road segment.

\subsubsection{The Management Input}

For security reasons, most of the roads in the study site were built as insloped surfaces. As a result, rill erosion develops along the inner side of roads. According to the field survey, there is little vegetation on the road surface and eroded rills. Therefore, the management layer input was selected as road-insloped with bare ditches in the management database.

\subsection{Data Analysis}

The Nash-Sutcliffe model efficiencies (MEs) (Nash \& Sutcliffe, 1970) were used to evaluate the precision of the modelling results according to the following equation:

\section{[1]}

where $M E$ is the model efficiency; $Q_{i}$ is the measured soil loss value; $Q_{c}$ is the WEPP predicted soil loss value; and $Q_{m}$ is the average of the measured soil loss values. The performance of $M E$ is given as follows: $M E$ $>0.75$ (very good), $0.75[?] \quad M E>0.65$ (good), 0.65[?] $M E>0.5$ (satisfactory), and 0.5 [?] (unsatisfactory) (Moriasi et al., 2007).

The effects of road segment terrain indexes on model efficiency were also evaluated by statistically analysing the data. The Pearson correlation coefficient (R) was used to evaluate the relationship between model deviation and terrain factors along road segments. Regression analyses were conducted to establish equations between the measured and predicted values. The coefficient of determination $\left(\mathrm{R}^{2}\right)$ was used to evaluate the equation performance. The results were reported at the $\alpha=0.05$ level of significance. All analyses were carried out with the SPSS 20.0 software package for Windows (IBM Corp., Armonk, NY, USA), while the graphics were generated with the ORIGIN 8.0 software package (OriginLab, Northampton, MA, USA).

[Insert Figure 2]

\section{RESULTS}

\subsection{Predicted Total Soil Loss from Road Segments}

Considering that the unpaved roads in the study site were maintained annually and the road surface rills were cleaned after the wet season, the measured soil loss rate could be treated as the annual erosion rate. Therefore, the TLS-measured rill soil loss rates were comparable to the WEPP-predicted soil loss. Figure 2 illustrates the WEPP-predicted rill soil loss rate for each road segment plotted with the measured values. The 20 road segments were classified into 7 groups according to different lengths and gradients. For the total dataset, the low NSE value of 0.05 implies an unsatisfactory WEPP prediction. This result is mainly due to the underestimated rill soil loss rates in the case of high erosion risks. A power function with an exponent of 0.65 could be used to describe the relationship between the measured and predicted soil loss rates. Further comparison was made under different road terrain conditions. In the case of road gradients lower than 5\%, all road lengths were shorter than $100 \mathrm{~m}$, and the WEPP-predicted soil losses were generally close to the 1:1 line (the green rectangle in Figure 2). When the road gradients were within the range from $5 \%$ to $10 \%$ (the blue points in Figure 2), the WEPP prediction would overestimate the soil losses, which were lower than $10 \mathrm{~kg} / \mathrm{m}^{2}$. For the measured soil loss higher than $10 \mathrm{~kg} / \mathrm{m}^{2}$, the WEPP model would result in underestimation. In the case of road gradients steeper than 10\% (the orange points in Figure 2), the soil losses were underestimated for 5 of 8 road segments. For the different lengths, the soil loss from most of the road segments shorter than $100 \mathrm{~m}$ was overestimated by the WEPP except for two segments with relatively high gradients (the rectangular points in Figure 2). In contrast, the majority of WEPP-predicted soil loss rates were underestimated for road segments longer than $100 \mathrm{~m}$ (the circle and triangle points in Figure 2). 
[Insert Figure 3]

\subsection{Predicted Detailed Soil Loss along Road Segments}

The WEPP-predicted soil loss rates along road segments were extracted according to the Plot Output data and illustrated with the TLS-measured values, as shown in Figure 3. The predicted WEPP values generally underestimated the peak soil loss rates for road segments longer than $100 \mathrm{~m}$, especially for some road segments with intensive soil loss and gully formation (R6, R9 and R20). On the other hand, the predicted soil loss rates were overestimated for many road segments shorter than $100 \mathrm{~m}$ (e.g., R10, R12, R15, R17 and R18). The $M E$ values in Figure 3 show that the WEPP simulation provided low efficiency compared with the measured soil loss along roads. Nevertheless, it is important to note that the WEPP-predicted soil loss rate followed a similar trend to that of the measured values. As illustrated in Figure 3, the ascending or descending sections of the WEPP simulation were generally consistent with the measured soil loss rate along most road segments. Further regression analyses were conducted to quantify the relationship between the predicted and measured soil losses. Table 3 lists the regression equations for each road segment. The measured soil loss could be expressed as linear or power functions of the predicted values. For most of the road segments, the $\mathrm{R}^{2}$ values were significant at the 0.05 level.

[Insert Table 3]

A consistent trend could also be found from the peak values. Although the simulated values generally underestimated the peak soil loss rate in most cases, the positions of the peak soil loss along road segments could be simulated by the WEPP. As illustrated in Figure 3, the positions of the WEPP-predicted and TLS-measured maximum soil loss rates were generally close to each other. Further analysis was performed by plotting the measured distance from the road top to the maximum peak soil loss rates with the predicted distances, as shown in Figure 4. The model efficiency of 0.6 illustrated satisfactory agreement between the predicted and measured values. It should be noted that the predicted distance was overestimated when the distance exceeded $100 \mathrm{~m}$, implying a delayed simulation of peak soil loss along road segments.

[Insert Figure 4]

\subsection{Factors that Influencing Model Performance}

To explore the factors that affect the efficiency of predicted soil loss along roads, the deviations were calculated as the WEPP-predicted values minus the TLS-measured values and then correlated with distance to road top and slope gradient along each road segment. Table 4 illustrates that many of the correlation coefficients ( $\mathrm{R}$ values) did not show significance at the 0.05 level due to the complexity of model deviations along road segments. However, most of the deviations were generally negatively related to the distance to the road top. This result implies that the underestimations of the WEPP output likely increase with distance to the road top. However, the $\mathrm{R}$ values between the deviation and slope gradient were more positive than the negative relationship, which means that the underestimation of WEPP tended to be reduced in the case of a steep gradient.

[Insert Table 4]

\section{[Insert Figure 5]}

The $\mathrm{R}^{2}$ values listed in Table 3 reflect the consistency between the WEPP-predicted and the TLD-measured soil losses along road segments. To further examine the efficiency of the predicted values, the $\mathrm{R}^{2}$ values were summarized according to the road terrain factors, including road segment length (Figure 5a), road slope gradient (Figure $5 \mathrm{~b}$ ) and road tortuosity (Figure $5 \mathrm{c}$ ). The results illustrated that the average $\mathrm{R}^{2}$ values were higher for shorter (L1), gentler (S1) and straighter (T1) road segments than for longer (L2 and L3), steeper (S2 and S3) and curved (T2 and T3) roads, implying relatively higher consistency between the predicted and measured soil loss along these roads. The functions developed in Table 3 were applied to revise the WEPP-predicted total soil losses for each road segment and then plotted with the TLS-measured values, as shown in Figure 8. The revised WEPP-predicted total soil loss rates were generally close to the TLS- 
measured values, and a linear function could be used to describe the relationship between the predicted and measured soil losses. The model efficiency of 0.86 illustrated the good fitness of the predicted soil loss rates after revision by the functions shown in Table 4.

[Insert Figure 6]

\section{Discussion}

\subsection{The Efficiency of WEPP for Total Road Segment Soil Loss Prediction}

As illustrated in Figure 2, the WEPP model generally provided a reasonable simulation of total soil loss rates for road segments with relatively low gradients and short lengths. This result implies that the unpaved road surface follows the opinion that the spatial scale for hillslope profile simulations is typically $<100 \mathrm{~m}$ in length (Nearing and Nicks, 1997). On the other hand, the predicted values lead to underestimation in the case of relatively high total soil losses occurring on steep and long road segments. This result implies the inability of the WEPP model to simulate high-intensity soil losses. Analogously, Elliot et al. (1991) reported that WEPP shear detachment might cause underestimation at higher erosion rates. It should be noted that the range of road slope gradient and length in this study is close to that reported in Elliot et al. (1995) and Brooks et al. (2006), and the simulation efficiency is also close to that reported by these studies.

The hillslope version of the WEPP applied in this study treated each road segment as an independent hillslope and calculated road surface soil loss according to terrain factors, including slope length and gradient. As a linear feature, the importance of road-intercepted upstream flow area in predicting road soil loss has been verified by $\mathrm{Cao}$ et al. (2021). An empirical model $(\mathrm{V}=0.205 L S+15.804 A-0.626)$ was built to predict erosion volumes according to road segment length (L), slope gradient (S) and intercepted upstream flow area (A). The WEPP-predicted soil loss amounts in this study were converted into erosion volumes and compared with those calculated using the equation developed by Cao et al. (2021). Figure 5 illustrates that the WEPP-predicted erosion volumes were generally lower than those calculated by the equation developed by Cao et al. (2021). The model efficiency for the WEPP erosion volume prediction was calculated as 0.42 , lower than that from the equation reported by Cao et al. (2021), which was 0.58. This result implies that the lack of road-intercepted upstream area might be another reason that leads to the underestimation of the hillslope version of the WEPP model.

\section{[Insert Figure 7]}

\subsection{The Efficiency of WEPP for Detailed Soil Loss Prediction along Roads}

Figure 3 shows that the WEPP-predicted detailed soil loss on short- or low-slope roads was relatively higher than the TLS-measured values. This result might be due to the interrill information in the detailed soil losses derived from the WEPP Plot Output data. For most parts of the road segments in Figure 3, the predicted detailed soil losses were lower than the measured values. This result could be explained by the fact that the soil detachment process in the WEPP model is simulated by the linearly critical shear stress model (Foster et al., 1995). The flow shear stress on a straight hillslope would be calculated as linearly increasing with slope length or gradient (Zhang et al., 2009). This means that the simulated soil loss should also linearly increase with slope length, similar to the detailed simulated soil losses along road segments illustrated by Figure 3. Nevertheless, Cao et al. (2011b) reported that soil detachment should be predicted as a power function rather than a linear function on unpaved road surfaces. This might explain the underestimation of the WEPP results on steep and long road segments, especially for the peak soil loss, which was generally underestimated in this study. Meanwhile, the sediment equilibrium theory, which addresses sediment detachment and transportation by overland flow, may be another reason for the WEPP underestimation. With increasing slope length, more sediment would be transported, and in turn, the calculated detachment rate would be reduced (Foster et al., 1995). This might explain the negative relationship between model deviation and slope length shown in Table 4, which implies increasing underestimations of WEPP output with distance to the road top. However, a steeper slope gradient along the hillslope would result in a higher soil detachment rate simulation and therefore could reduce the underestimation of the WEPP compared with the measured soil losses. The 
slope gradient variation and its effect on WEPP soil loss prediction are also supported by Zhang (2017), who found that an increased slope leads to a maximum soil loss along hillslopes.

Although the WEPP model underestimated soil loss from steep and long road segments, the predicted values followed a similar trend to the TLS-measured values. The significant fitness of the regression equations in Table 2 verified the high consistency between the WEPP-simulated and TLS-measured soil losses. The model efficiency calculated in Figure 4 illustrates that the peak soil loss positions could be reasonably estimated by the WEPP model. This verified the capability of the WEPP model in describing road slope variation and quantifying the response of road surface erosion. Additionally, road terrain factors would influence the abovementioned consistency. Figure 5 illustrates that the averaged determination coefficients in Table 3 were relatively low for long and steep road segments. This result supported the abovementioned effect of slope gradient and length in determining flow energy dynamics along hillslopes. Zhang (2017) reported that the WEPP model was extremely sensitive to slope steepness at longer slope lengths. Therefore, a longer road length or steeper gradient might result in a larger deviation between the WEPP-predicted and the TLS-measured soil losses in this study. Additionally, as a linear feature, road tortuosity might play a role in determining the efficiency of the model results. The relatively low determination coefficient in large road tortuosity in Figure 5 illustrates that the highly curved road segments tend to lead to a large deviation between the WEPP-predicted and TLS-measured soil loss rates. This result could be explained by the fact that the WEPP hillslope version treats road segments as straight slopes. However, the curved road segment implies a large variation in flow energy and sediment transport along the road surface compared with a straight hillslope. Therefore, these conditions might result in different soil loss processes along road segments than the WEPP simulations.

\subsection{Implication and Limitations of this Study}

The results of this study showed that the WEPP hillslope version could provide reasonable predictions of soil loss from short gentle roads in the red soil region of China. It also illustrated that the model inputs, including soil parameters such as rill erodibility and hydraulic conductivity, suggested by the WEPP: Road were acceptable for unpaved roads in the study area. Therefore, the WEPP hillslope version could be used to calculate the total soil loss amount from unpaved road surfaces in the case of road lengths less than $100 \mathrm{~m}$ and with relatively low gradients. Meanwhile, the WEPP simulation could fit the detailed soil loss and the peak erosion in long road segments despite the underestimation. This result implies that the model could predict high soil loss risk points along roads. This information would be helpful for road conservation and erosion control. The equations developed in Table 3 could be used to improve the precision of the WEPP simulation. To further enhance the WEPP efficiency for road erosion modelling, the intercepted upstream area and road tortuosity should also be considered in future studies.

It should also be noted that there are limitations in this study. Since the measured soil loss amount is essentially rill erosion, which is calculated based on one-time TLS scanning and a referenced road surface (Cao et al., 2021), neither the interrill erosion nor the sediment deposition can be precisely measured. Although interrill erosion composed a very small percent of most roads with high soil loss in this study, it might contribute to the deviation of simulation compared with the measured soil losses along some short and gentle road segments. Further multiperiod dynamic TLS-aided erosion measurements should be conducted to provide more reasonable criteria. Meanwhile, the soil inputs, including rill erodibility, critical shear stress and effective hydraulic conductivity, used in this study were the same for all road segments. Considering the variation in soil properties throughout the watershed, the detailed road surface soil parameters should be quantified for different road segments or along roads.

\section{CONCLUSIONS}

This study validated the performance of the WEPP hillslope version in predicting unpaved road soil loss in the red soil region of South China. The results illustrated that the WEPP-simulated soil loss generally provided reliable estimation for road segments shorter than $100 \mathrm{~m}$ and with gradients lower than $10 \%$. In the case of road lengths exceeding $100 \mathrm{~m}$ or gradients exceeding 10\%, the WEPP simulation would underestimate 
the total road surface soil loss. The detailed prediction of soil loss along roads revealed that underestimation mainly occurred in the case of the peak erosion segments, which could be attributed to the linear critical shear stress model that cannot fit the nonlinear mechanism of rill detachment in road surfaces. Meanwhile, the underestimations of WEPP output along roads likely increase with slope length but decline with slope gradient, which might be explained by the sediment equilibrium theory. Despite the underestimation, the WEPP-simulated soil losses showed a close relationship and were consistent with the trend of measured values along road segments. The maximum soil loss positions could be reasonably predicted by the WEPP model. The comparison between the WEPP-simulated total soil loss and our previous studies reflected that the lack of upstream flow area might also lead to the underestimation of steep and long road segments in this study. In addition, the slope gradient, road length and road tortuosity were found to negatively affect the efficiency of the WEPP simulation. The above results are helpful in evaluating unpaved road soil erosion and expanding the range of WEPP applications.

\section{ACKNOWLEDGEMENTS}

The work in this paper is part of Projects 41807077 and 41571273 , which are supported by the National Natural Science Foundation of China. We greatly thank Dr. W.J. Elliot of the Rocky Mountain Research Station (USDA Forest Service) for valuable suggestions about WEPP modelling.

The authors declare no conflicts of interest.

\section{DATA AVAILABILITY STATEMENT:}

The data that support the findings of this study are available from the corresponding author upon reasonable request.

\section{REFERENCES}

Akay, A. E., Erdas, O., Reis, M., \& Yuksel, A. (2008). Estimating sediment yield from a forest road network by using a sediment prediction model and GIS techniques. Building and Environment, 43(5),687695. https://doi.org/ 10.1007/s10669-007-9137-1.

Anderson, D. M., \& MacDonald, L. H. (1998). Modeling road surface sediment production using a vector geographic information system.Earth Surface Processes and Landforms, 23, 95-107. https://doi.org/10.1002/(SICI)1096-9837(199802)23:23.0.CO;2-1.

Benda, L., James, C., Miller, D., \& Andras, K. (2019). Road erosion and delivery index (READI): A model for evaluating unpaved road erosion and stream sediment delivery. Journal of the American Water Resources Association, 55: 459-484. https://doi.org/10.1111/1752-1688.12729.

Boise Cascade Corporation. Technical Documentation for SEDMODL version 2. 2003, 42p.

Brooks, E. S., Boll, J., Elliot, W. J., \& Dechert, T. (2006). Global Positioning System/GIS-based approach for modeling erosion from large road networks. Journal of Hydrologic Engineering, 11, 418-426. https://doi.org/10.1061/(ASCE)1084-0699(2006)11:5(418).

Brown, K. R., Michael Aust, W., \& McGuire, K. J. (2013). Sediment delivery from bare and graveled forest road stream crossing approaches in the Virginia Piedmont. Forest Ecology and Management, 310. https://doi.org/10.1016/j.foreco.2013.09.031.

Cao, L. X., Wang, Y., \& Liu, C. (2021). Study of unpaved road surface erosion based on terrestrial laser scanning. CATENA, 199, 105091. https://doi.org/10.1016/j.catena.2020.105091.

Cao, L. X., Zhang, K. L., Dai, H. L., \& Guo, Z. L. (2011a). Estimation of sediment yield during expressway construction period. Journal of Highway and Transportation Research and Development, 32, 292-297. (in Chinese with English abstract).

Cao, L. X., Zhang, K. L., Dai, H. L., \& Guo, Z. L., (2011b). Modeling soil detachment on unpaved road surfaces on the Loess Plateau.Transactions of the ASABE . 54, 1377-1384. 
https://doi.org/10.13031/2013.39039.

Cao, L. X., Zhang, K. L., Dai, H. L., \& Liang, Y. (2015). Modeling interrill erosion on unpaved roads in the loess plateau of China.Land Degradation $\& 3$ Development, 26, 825-832. https://doi.org/10.1002/ldr.2253.

Cole, R. P., Bladon, K. D., Wagenbrenner, J. W., \& Coe, B. R. (2020). Hillslope sediment production after wildfire and post-fire forest management in northern California. Hydrological Processes,(42):5242-5259. https://doi.org/10.1002/hyp.13932.

Damian, F. (2003). Cross-drain placement to reduce sediment delivery from forest roads to streams. MS thesis. Seattle, Wash.: University of Washington, College of Forest Resources.

Dangle, C. L., Bolding, M. C., Aust, W. M., Barrett, S. M., \& Schilling, E. B. (2019). Best management practices influence modeled erosion rates at forest haul road stream crossings in Virginia.Journal of the American Water Resources Association, 55, 1169-1182. https://doi.org/10.1111/1752-1688.12762.

Dubé, K., W. Megahan., \& McCalmon, M. (2004). Washington Road Surface Erosion Model (WARSEM) Manual . Olympia, WA.: WA. Dept. of Natural Resources.

Dun, S., Wu, J. Q., Elliot, W. J., Robichaud, P. R., Flanagan, D. C., Frankenberger, J. R., Brown, R. E., \& Xu, A. C. (2009). Adapting the Water Erosion Prediciton Project (WEPP) model for forest applications. Journal of Hydrology, 366: 46-54. https://doi.org/10.1016/j.jhydrol.2008.12.019.

Elliot, W. J., (2013). Erosion processes and prediction with WEPP technology in forests in the Northwestern U.S. Transactions of the ASABE, 56, 563-579. https://doi.org/10.13031/2013.42680.

Elliot, W. J., Elliot, A.V., Wu, Q., \& Laflen, J. M. (1991). Validation of WEPP model with rill erosion plot data. American Society of Agricultural Engineers International Winter Meeting. 11p.

Elliot, W. J., Foltz, R. B., \& Luce, C. H. (1995). Validation of the Water Erosion Prediction Project (WEPP) model for low-volume forest roads. Pp. 178-186 in Proceedings of the 6th International Conference on Lowvolume Roads, Washington, DC.

Elliot, W. J., \& Hall, D. E. (2010). Disturbed WEPP Model 2.0. Ver. 2014.04.14. Moscow, ID: U.S. Department of Agriculture, Forest Service, Rocky Mountain Research Station.

Fernández, C., \& Vega, J. A. (2018). Evaluation of the rusle and disturbed wepp erosion models for predicting soil loss in the first year after wildfire in NW Spain. Environmental Research, 165:279-285. https://doi.org/10.1016/j.envres.2018.04.008.

Foster, G. R., Flanagan, D. C., Nearing, M. A., Lane, L. J., Risse, L. M., \& Finkner, S. C. (1995). Hillslope erosion component. In USDA-Water Erosion Prediction Project, Hillslope Profile and Watershed Model Documentation, NSERL Report 10. Flanagan, D. C. and Nearing, M. A. eds. West Lafayette, Ind.: USDAARS National Soil Erosion Research Laboratory.

Fu, B., Newham, L. T. H., \& Field, J. B. (2008). Modeling erosion and sediment delivery from unsealed roads in southeast Australia. Mathematics and Computers in Simulation,79(9): 2679-2688. https://doi.org/10.1016/j.matcom.2008.10.001.

Gucinski, H., Furniss, M. J., Ziemer, R. R., \& Brookes, M. H. (2001). Forest roads: a synthesis of scientific information. General Technical Report PNWGTR-509, (pp. 103). Portland, OR: U.S. Department of Agriculture, Forest Service, Pacific Northwest Research Station.

Guerra, A. J. T., \& Silva, S. (2011). Predicting soil loss and runoff from forest roads and seasonal cropping systems in Brazil using WEPP. In: Handbook of erosion modeling, Eds: Morgan R.P.C. and Nearing M.A. Pp 186-194. https://doi.org/10.1002/9781444328455.ch10.

Guo, W., Bai, Y., Cui, Z., Wang, W., Li, J., \& Su, Z. (2021). The impact of concentrated flow and slope on unpaved loess road erosion on the Chinese Loess Plateau. Land Degradation \& Development, 32(2): 914-925. 
https://doi.org/10.1002/ldr.3774.

Kinnell, P. I. A., Wang, J., \& Zheng, F. (2018). Comparison of the abilities of WEPP and the USLE-M to predict event soil loss on steep loessal slopes in China. CATENA, 171. https://doi.org/10.1016/j.catena.2018.07.007.

Moriasi, D. N., Arnold, J. G., Van Liew, M. W., Bingner, R. L., Harmel, R. D., \& Veith, T. L. (2007). Model evaluation guidelines for systematic quantification of accuracy in watershed simulations. Trans. ASABE. 50, 885-900. https://doi.org/10.13031/2013.23153.

Motha, J. A., Wallbrink, P. J., Hairsine, P. B., \& Grayson, R. B. (2004). Unsealed roads as suspended sediment sources in an agricultural catchment in south-eastern Australia. Journal of Hydrology, 286: 1-18. https://doi.org/10.1016/j.jhydrol.2003.07.006.

Nash, J. E., \& Sutcliffe, J. V., (1970). River flow forecasting through conceptual models, Part 1-A discussion of principles. Journal of Hydrology 10, 282-290. https://doi.org/10.1016/0022-1694(70)90255-6.

Nearing M. A., Foster G. R., Lane, L. J., \& Finker, S. C. (1989). A process-based soil erosion model for USDA-water erosion prediction project technology. Transactions of the ASAE 32: 1587-1593. https://doi.org/10.13031/2013.31195.

Nearing, M. A., \& Nicks, A. D. (1997). Evaluation of the Water Erosion Prediction Project (WEPP) model for hillslopes. NATO ASI Ser. 55:43-53.

Nicks, A. D., Lane, L. J., \& Gander G. A. (1995). Weather generator. In USDA-Water Erosion Prediction Project, Hillslope Profile and Watershed Model Documentation, NSERL Report 10. Flanagan, D.C. and Nearing, M.A. eds. West Lafayette, Ind.: USDA-ARS National Soil Erosion Research Laboratory.

Parsakhoo, A., Lotfalian, M., Kavian, A., \& Hosseini, S. A. (2014). Prediction of the soil erosion in a forest and sediment yield from road network through GIS and SEDMODL. International Journal of Sediment Research, 29: 118-125. https://doi.org/10.1016/S1001-6279(14)60027-5.

Ramos-scharrón, C. E. (2021). Impacts of off-road vehicle tracks on runoff, erosion and sediment delivery-a combined field and modeling approach. Environmental Modelling 63 Software, 136: 104957. https://doi.org/10.1016/j.envsoft.2020.104957.

Renschler, C. S., \& Zhang, H. (2020). Long-term, process-based, continuous simulations for a cluster of six smaller, nested rangeland watersheds near Tombstone, AZ (USA): Establishing a baseline for event-based runoff and sediment yields. Science of the Total Environment, 717, 137089. https://doi.org/10.1016/j.scitotenv.2020.137089.

Revuelta-Acosta, J. D., Flanagan, D. C., Engel, B. A., \& King, K. W. (2021). Improvement of the Water Erosion Prediction Project (WEPP) model for quantifying field scale subsurface drainage discharge.Agricultural Water Management, 244. https://doi.org/10.1016/j.agwat.2020.106597.

Sheridan, G. J., Noske, P. J., Whipp, R. K., \& Wijesinghe, N. (2006). The effect of traffic volume and road water-status on water quality from forest roads. Hydrological Processes, 20, 1683-1699. https://doi.org/10.1002/hyp.5966.

Shi, D. M. (1985). Soil erosion, soil conservation and ecosystems in the granitic regions of South China. Soil Water Conservation in China 12: 6-10. https://doi.org/ 10.14123/j.cnki.swcc.1985.12.002. (in Chinese with English abstract).

Tarolli, P. (2016). Humans and the Earth's surface. Earth Surface Processes and Landforms, 41: 2301-2304. https://doi.org/10.1002/ESP.4059.

Vinci, A., Todisco, F., \& Mannocchi, F. (2016). Calibration of manual measurements of rills using Terrestrial Laser Scanning. CATENA,140, 164-168, https://doi.org/10.1016/j.catena.2016.01.026. 
Wemple, B. C., Clark, G. E., Ross, D. S., \& Rizzo, D. M. (2017). Identifying the spatial pattern and importance of hydro-geomorphic drainage impairments on unpaved roads in the northeastern USA.Earth Surface Processes and Landforms, 42, 1652-1665. https://doi.org/10.1002/esp.4113.

Wischmeier, W. H., \& Smith, D. D. (1965). Predicting rainfall erosion losses from cropland east of the Rocky Mountains. Agricultural Handbook, Vol. 282. US Government Print Office, Washington, DC.

Yang, B., Wang, W. L., Guo, M. M., Guo, W. Z., Wang, W. X., Kang, H. L., Zhao, M., \& Chen, Z. X. (2019). Soil erosion of unpaved loess roads subjected to an extreme rainstorm event: a case study of the Jiuyuangou watershed on the Loess Plateau, China. Journal of Mountain Science, 16: 1396-1407. https://doi.org/10.1007/s11629-018-5211-z.

Zhang, J. X., Wu, J. Q., Chang, K., Elliot, W. J., \& Dun, S. (2009). Effects of DEM source and resolution on WEPP hydrologic and erosion simulation: A case study of two forest watersheds in northern Idaho. Transactions of the ASABE, 52: 447-457.

Zhang, X. C. (2017). Evaluating water erosion prediction project model using Cesium-137derived spatial soil redistribution data. Soil Science Society of America Journal, 81, 179-188. https://doi.org/10.2136/sssaj2016.06.0172.

Zhao, Y., Zhang, Y., Yuan, M., Yang, M., \& Deng, J. (2021). Estimation of initiation thresholds and soil loss from gully erosion on unpaved roads on China's Loess Plateau. Earth Surface Processes and Landforms. https://doi.org/10.1002/esp.5102.

Zheng, F., Zhang, X. C., Wang, J., \& Flanagan, D. C. (2020). Assessing applicability of the WEPP hillslope model to steep landscapes in the northern Loess Plateau of China. Soil and Tillage Research,197(C). https://doi.org/10.1016/j.still.2019.104492.

Ziegler, A. D., \& Giambelluca, T. W. (1997). Importance of rural roads as source areas for runoff in mountainous areas of northern Thailand. Journal of Hydrology, 196 (1-4): 204-229. https://doi.org/10.1016/S00221694(96)03288-X.

Table 1. Terrain factors and the TLS-measured erosion rate for each road segment

\begin{tabular}{llllllllll}
\hline CODE & $\begin{array}{l}\text { Length } \\
(\mathrm{m})\end{array}$ & Slope $(\%)$ & $\begin{array}{l}\text { Road } \\
\text { Tortuosity* }\end{array}$ & $\begin{array}{l}\text { Erosion } \\
\left(\mathrm{kg} / \mathrm{m}^{2} / \mathrm{a}\right)\end{array}$ & CODE & $\begin{array}{l}\text { Length } \\
(\mathrm{m})\end{array}$ & Slope (\%) & $\begin{array}{l}\text { Road } \\
\text { Tortuosity* }\end{array}$ & $\begin{array}{l}\text { Er } \\
(\mathrm{k}\end{array}$ \\
\hline R1 & 340.0 & 13.9 & 1.43 & 33.08 & $\mathrm{R} 11$ & 91.3 & 1.5 & 1.50 & 0.5 \\
R2 & 45.2 & 10.4 & 1.03 & 20.87 & R12 & 89.0 & 5.0 & 1.37 & 1.7 \\
R3 & 72.4 & 6.3 & 1.11 & 25.98 & R13 & 85.1 & 3.8 & 2.14 & 1.8 \\
R4 & 208.5 & 14.8 & 1.21 & 19.52 & R14 & 159.3 & 9.3 & 1.27 & 4.1 \\
R5 & 103.4 & 17.4 & 1.14 & 39.32 & R15 & 81.6 & 4.0 & 1.07 & 0.7 \\
R6 & 195.0 & 9.3 & 1.41 & 45.58 & R16 & 389.5 & 12.9 & 1.67 & 12 \\
R7 & 101.1 & 8.3 & 1.17 & 18.11 & R17 & 82.4 & 6.5 & 1.03 & 0.6 \\
R8 & 300.5 & 10.7 & 1.26 & 7.79 & R18 & 55.0 & 3.5 & 1.12 & 0.5 \\
R9 & 213.3 & 9.0 & 1.18 & 42.54 & R19 & 251.1 & 10.5 & 1.97 & 13 \\
R10 & 106.4 & 6.9 & 1.27 & 0.58 & R20 & 271.4 & 12.3 & 1.21 & 36 \\
\hline
\end{tabular}

* Road tortuosity was calculated as the straight length between two ending points of a road segment divided by the total road segment length

Table 2. Soil parameters for road surface erosion modelling with WEPP

\begin{tabular}{ll}
\hline Input soil parameters & Values \\
\hline Albedo of the bare dry surface soil & 0.6
\end{tabular}




\begin{tabular}{ll}
\hline Input soil parameters & Values \\
\hline Initial saturation level of the soil profile porosity $(\mathrm{m} / \mathrm{m})$ & 0.5 \\
Baseline interrill erodibility parameter $\left(\mathrm{kg}^{*} \mathrm{~s} / \mathrm{m}^{4}\right)$ & 500000 \\
Baseline rill erodibility parameter $(\mathrm{s} / \mathrm{m})$ & 0.0001 \\
Baseline critical shear parameter $\left(\mathrm{N} / \mathrm{m}^{2}\right)$ & 2 \\
Effective hydraulic conductivity of surface soil $(\mathrm{mm} / \mathrm{h})$ & 3.8 \\
Depth from soil surface to bottom of soil layer $(\mathrm{mm})$ & 200 \\
\hline
\end{tabular}

Table 3. TLS-measured soil loss as a function of WEPP-predicted soil loss along roads

\begin{tabular}{llllllllll}
\hline CODE & Equation & $\mathrm{R}^{2}$ & $\mathrm{SIG}$ & $\mathrm{N}$ & $\mathrm{CODE}$ & Equation & $\mathrm{R}^{2}$ & $\mathrm{SIG}$ & $\mathrm{N}$ \\
\hline $\mathrm{R} 1$ & $\mathrm{Y}=1.555 \mathrm{x}-1.044$ & 0.507 & 0.000 & 67 & $\mathrm{R} 11$ & $\mathrm{Y}=0.892 \mathrm{x}-0.182$ & 0.523 & 0.001 & 18 \\
$\mathrm{R} 2$ & $\mathrm{Y}=0.042 \mathrm{x}^{3.824}$ & 0.926 & 0.000 & 9 & $\mathrm{R} 12$ & $\mathrm{Y}=0.468 \mathrm{x}+0.086$ & 0.506 & 0.006 & 13 \\
$\mathrm{R} 3$ & $\mathrm{Y}=0.297 \mathrm{x}^{2.665}$ & 0.782 & 0.000 & 13 & $\mathrm{R} 13$ & $\mathrm{Y}=0.797 \mathrm{x}+0.526$ & 0.053 & 0.472 & 12 \\
$\mathrm{R} 4$ & $\mathrm{Y}=0.955 \mathrm{x}^{0.856}$ & 0.283 & 0.000 & 40 & $\mathrm{R} 14$ & $\mathrm{Y}=0.441 \mathrm{x}+0.991$ & 0.514 & 0.000 & 25 \\
R5 & $\mathrm{Y}=0.270 \mathrm{x}+16.44$ & 0.008 & 0.712 & 20 & $\mathrm{R} 15$ & $\mathrm{Y}=0.722 \mathrm{x}-0.666$ & 0.746 & 0.006 & 8 \\
R6 & $\mathrm{Y}=6.934 \mathrm{x}-41.49$ & 0.278 & 0.039 & 36 & $\mathrm{R} 16$ & $\mathrm{Y}=0.450 \mathrm{x} .015$ & 0.645 & 0.000 & 76 \\
R7 & $\mathrm{Y}=2.657 \mathrm{x}+3.68$ & 0.312 & 0.013 & 19 & $\mathrm{R} 17$ & $\mathrm{Y}=3.022-0.295 \mathrm{x}$ & 0.106 & 0.675 & 4 \\
R8 & $\mathrm{Y}=0.867 \mathrm{x}^{0.805}$ & 0.419 & 0.000 & 58 & $\mathrm{R} 18$ & $\mathrm{Y}=2.095 \mathrm{x}-1.450$ & 0.688 & 0.041 & 6 \\
R9 & $\mathrm{Y}=7.319 \mathrm{x}-42.51$ & 0.591 & 0.000 & 42 & $\mathrm{R} 19$ & $\mathrm{Y}=1.098 \mathrm{x}-3.369$ & 0.068 & 0.131 & 35 \\
R10 & $\mathrm{Y}=1.46-0.140 \mathrm{x}$ & 0.125 & 0.235 & 13 & $\mathrm{R} 20$ & $\mathrm{Y}=1.841 \mathrm{x}-1.257$ & 0.202 & 0.001 & 51 \\
\hline
\end{tabular}

Table 4. The correlation coefficients between model deviation and influential factors

\begin{tabular}{llllllllllll}
\hline Code & Distance & Distance & Slope & Slope & N & Code & Distance & Distance & Slope & Slope & N \\
\hline & Pearson R & SIG & Pearson R & SIG & & & Pearson R & SIG & Pearson R & SIG & \\
R1 & -0.015 & 0.906 & $-0.322^{* *}$ & 0.008 & 67 & R11 & 0.325 & 0.189 & -0.073 & 0.780 & 18 \\
R2 & $-0.761^{*}$ & 0.017 & 0.003 & 0.995 & 9 & R12 & -0.354 & 0.235 & 0.373 & 0.233 & 13 \\
R3 & $-0.705^{* *}$ & 0.007 & -0.173 & 0.590 & 13 & R13 & $-0.653^{*}$ & 0.021 & 0.243 & 0.447 & 12 \\
R4 & 0.144 & 0.374 & -0.204 & 0.213 & 40 & R14 & -0.331 & 0.099 & $0.689^{* *}$ & 0.000 & 26 \\
R5 & 0.277 & 0.224 & 0.019 & 0.937 & 21 & R15 & 0.118 & 0.780 & 0.475 & 0.234 & 8 \\
R6 & $-0.466^{* *}$ & 0.004 & 0.076 & 0.660 & 36 & R16 & $0.451^{* *}$ & 0.000 & 0.035 & 0.763 & 76 \\
R7 & -0.025 & 0.919 & -0.290 & 0.243 & 19 & R17 & -0.617 & 0.383 & 0.475 & 0.525 & 4 \\
R8 & -0.119 & 0.370 & $0.369^{* *}$ & 0.004 & 59 & R18 & -0.499 & 0.314 & 0.632 & 0.178 & 6 \\
R9 & $-0.426^{* *}$ & 0.005 & $-0.368^{*}$ & 0.016 & 42 & R19 & 0.220 & 0.204 & 0.053 & 0.761 & 35 \\
R10 & $-0.864^{* *}$ & 0.000 & $0.843^{* *}$ & 0.000 & 13 & R20 & 0.034 & 0.815 & -0.232 & 0.109 & 50 \\
\hline
\end{tabular}

\section{FIGURE LEGENDS}

Figure 1. The monthly averaged precipitation of 2017 and 2018 at the study site

Figure 2. The relationship between the TLS-measured and WEPP-predicted rill soil loss values

L1, L2 and L3 represent road segment lengths shorter than $100 \mathrm{~m}, 100 \mathrm{~m}-200 \mathrm{~m}$ and longer than 200 $\mathrm{m}$, respectively. S1, S2 and S3 represent road gradients lower than 5\%, 5\%-10\% and higher than 10\%, respectively.

Figure 3. The TLS-measured and WEPP-predicted detailed soil loss along road segments 
Figure 4. The measured distance to the peak soil loss as plotted with the predicted values Figure 5. Average determination coefficient in Table 3 as summarized according to road terrain factors

L1, L2 and L3 represent road segment lengths shorter than $100 \mathrm{~m}, 100 \mathrm{~m}-200 \mathrm{~m}$ and longer than 200 $\mathrm{m}$, respectively. S1, S2 and S3 represent road gradients lower than 5\%, 5\%-10\% and higher than 10\%, respectively. T1, T2 and T3 represent road tortuosity less than 1.2, 1.2-1.4 and higher than 1.4, respectively.

Figure 6. The measured soil loss plotted with the revised WEPP-predicted soil loss rates

Figure 7. Comparison of total soil losses predicted with WEPP and the equation built by Cao et al. (2021)

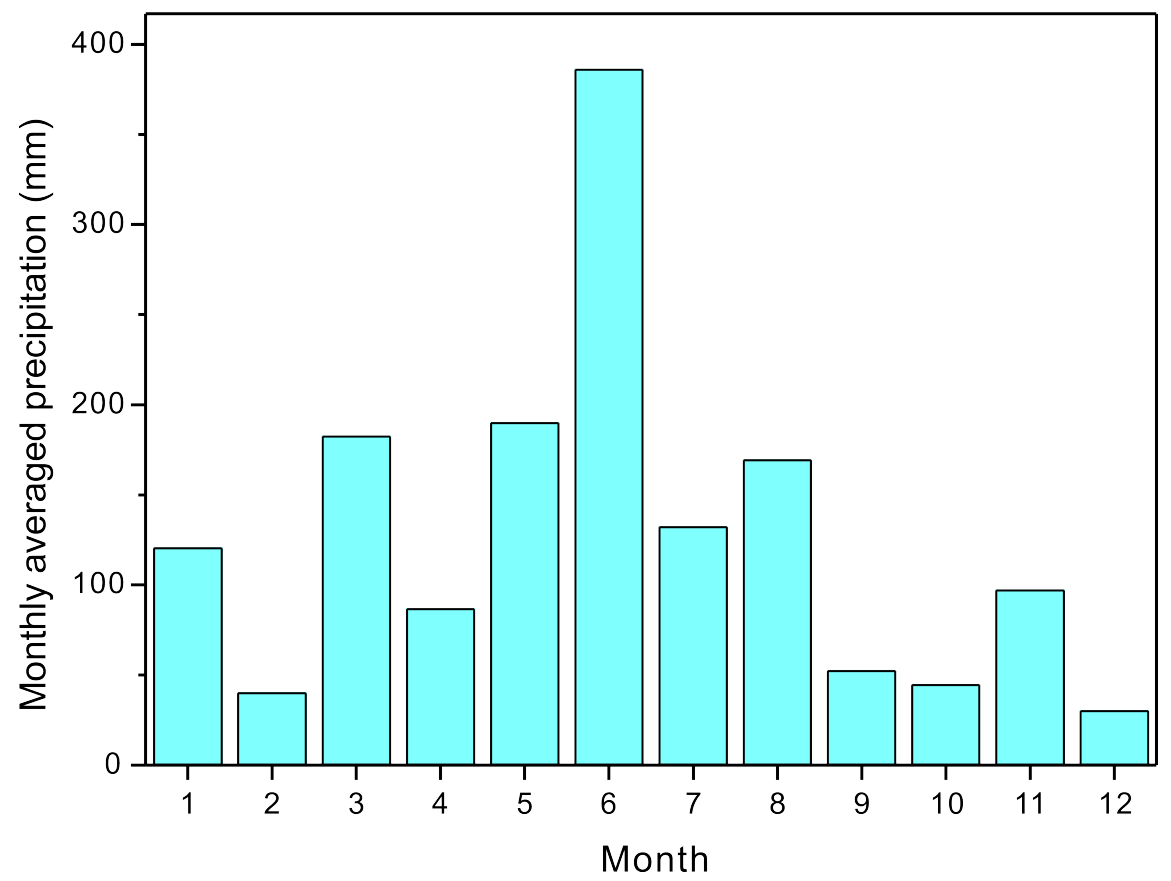



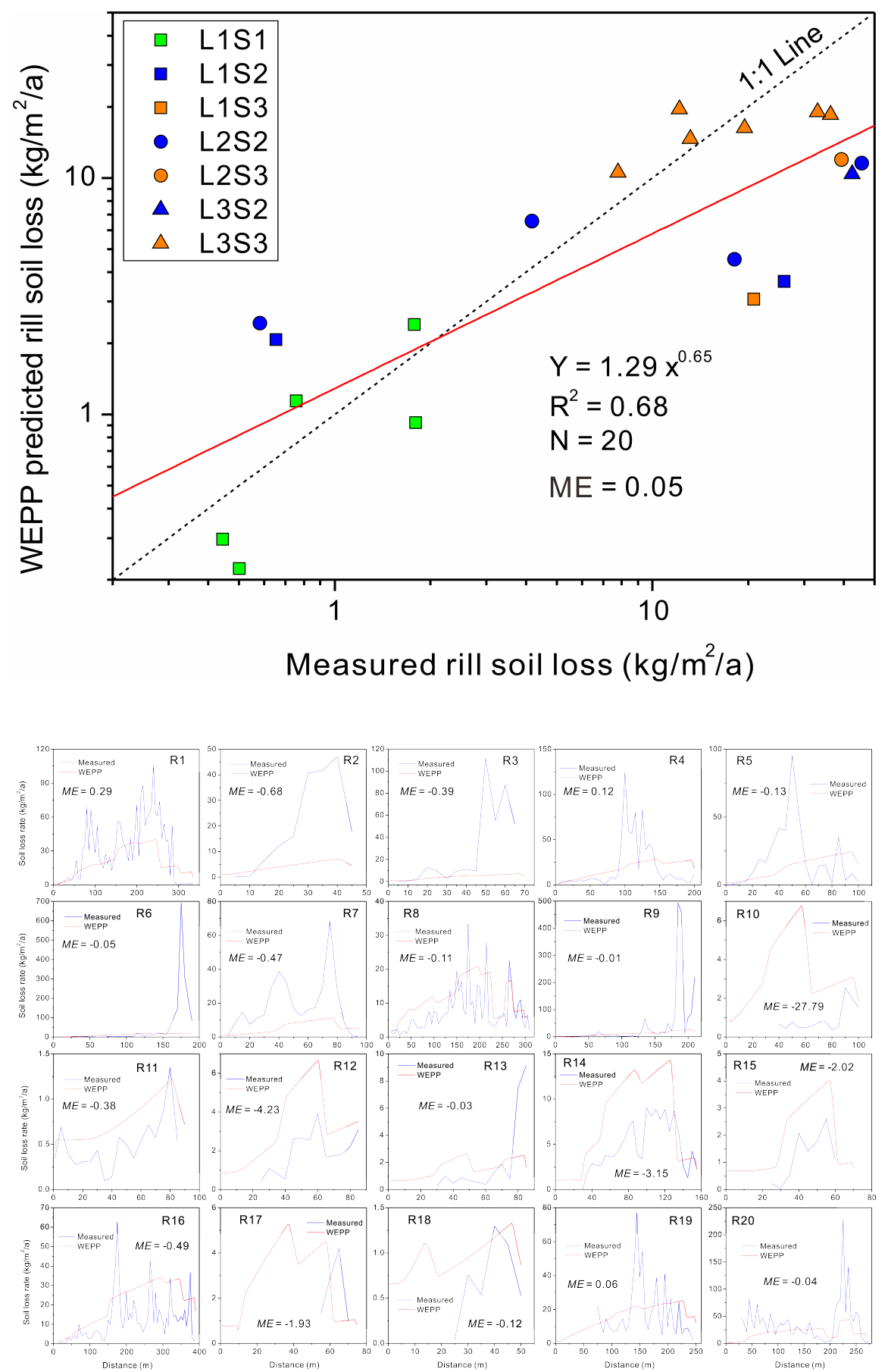

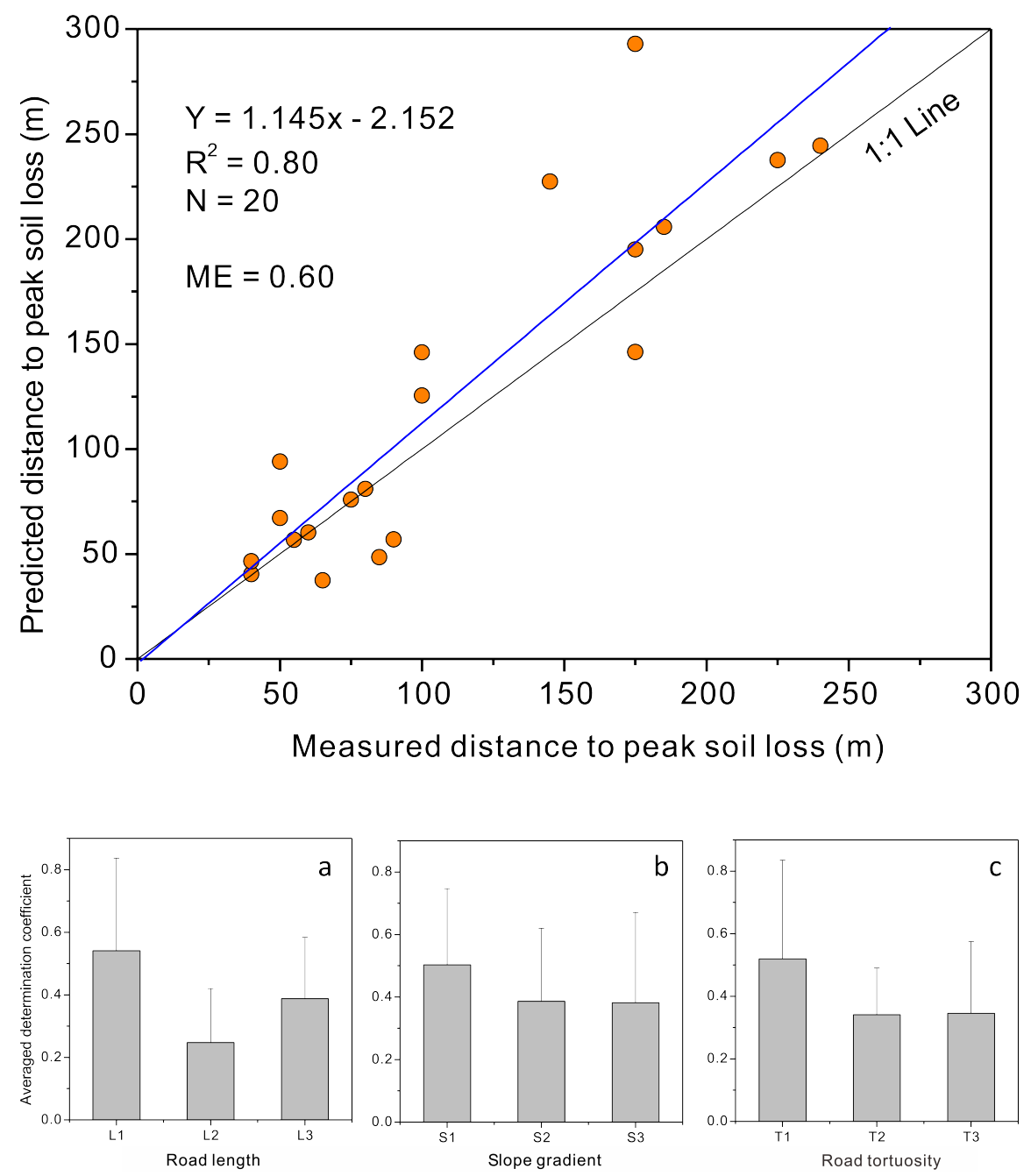

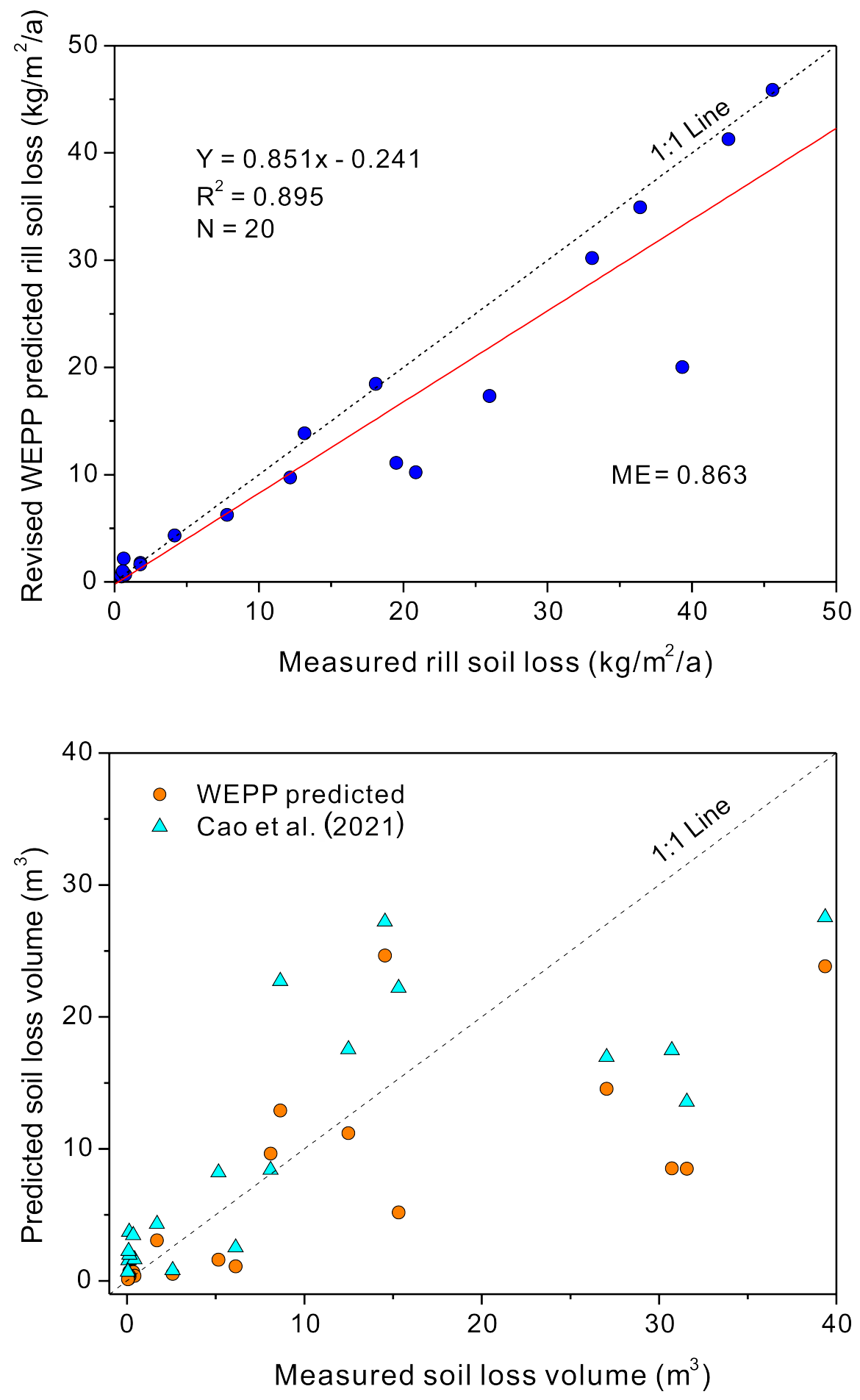